\title{
Changes in Managerial Functions in Agriculture
}

\author{
Csaba Berde \\ University of Debrecen, Centre for Agricultural Sciences, \\ Faculty of Agricultural Economics and Rural Development, \\ Department of Management Science, Debrecen
}

\section{SUMMARY}

Managerial activity is a process constituted by well separable functions, tasks. The functions and the content of managerial activity are influenced by several factors.

This multi-sided affectedness focused our attention on the analysis of management tasks. We aimed to formulate responses for the questions how and to what extent the activities and tasks of organizations define the tasks and functions at the given organization. On the basis of interview surveys, we analyzed the following managerial tasks: functions concerning information, communication, planning, decision-making, organization, control. The interviewed had to rank the factors influencing management tasks on a scale ranging from one to five. On the basis of the activities and tasks of organizations, we defined three types. The scope of this study does not allow us to publish all the results related to the above-mentioned managerial functions, so we can only present some, which are of interest.

Our findings suggest that the realization of certain management functions is influenced by several factors. Without striving for completeness, we could only evaluate 9-11 factors per function. The evaluation of information sources is considerably differentiated in terms of the activities, tasks of organizations. In the assessment of plans, the potentials for realization and repetition were judged differently, whereas non-organization changes and individual planning similarly. The findings of impact factors in decision making are largely different, as well in terms of organizational activities, but all the interviewed ranked the interests of the organization high. Analysis on control indicated that managers attributed higher importance to issues of content than to methodological ones.

Our investigations follow Fayol's classical groups based on managerial tasks. We studied the following five tasks in the process of management: information tasks, planning, decisionmaking, instructions and control. We performed our studies with the inclusion of agricultural organization managers, with questionnaire surveys. The interviewed were asked to qualify the impact factors on the five investigated management tasks on a scale ranging from 1-5. We identified the following company groups: small company, medium company and large company.

We performed our analysis on the basis of company sizes as well, seeking to formulate responses on how size influences the qualification of the investigated factors.

Our findings suggest that the interviewed company managers attribute higher than average roles to the tasks of the management process. The qualification, ranking of management tasks are considerably influenced by company sizes. Relationships and venues are important in the implementation of information tasks, whereas the viability of plans is essential in the process of planning. Usefulness and company interests are highlighted in decision-making. In the case of instructions and decision-making, we stressed the significance of content elements as opposed to formal ones.

The process of management integrates several interrelated tasks. In management activities tasks are built on each other in a logical order, as decisionmaking always precedes decision implementation or managerial control. Naturally, managerial tasks can be interpreted individually as well. These tasks can be separated, investigated and researched individually, as well.

Our primary aim is to identify the tasks constituting the process of management. Dobák et al. (1995) regard Fayol's classical groups from the early XX.th century as still valid: planning, organization, personal leadership, coordination and control. Several researchers, have studied management functions and classified them on the basis of various standpoints. The content of managerial work is influenced by scores of factors, such as historical periods. Berki (2001) claims that managers have to realize completely different tasks in the so-called 'info-era' than in the earlier 'smoke-era'. In the future's management tasks of enhanced prestige, Kerékjártó (2001) points out the importance of motivation, whereas Juhász (2001) and Dienesné (2000) enhance the significance of human resource management. Berki-Berde (1999) define the complex and multi-sided task of time management as the basic function of managerial work in the future. Láczay (1999) suggests that land reforms have complex and significant influences, such as the disintegration and reorganization of the economic elite. Naturally, the reorganization of the elite results in the formation of a new managerial layer and, consequently, new managerial tasks (Láczay, 2001). The reorganization of paradigms is essential for the interpretation and scientific investigation of managerial functions and tasks (Berki, 1998). New social values, as well as inner and outer personal characteristics, are identified. 'In terms of social values, we are attractive if we have a repertoire of positive inner and outer qualities' (Berki-Berde, 2000). Dienesné (1999) analyzed the motivations of managerial activities by tests on values and preferences. She emphasized that 'theories on motivation became widespread in the areas of agriculture as well in the last century, but research was rather scarce (Dienesné et al., 2000).

The realization of management activities and the way one performs these tasks, functions largely depend on the manager's personality. Individual managers exert managerial functions to a different extent, proportion and content. Judgements and preferences, basic beliefs, attitude, task or relationship-oriented managerial style and the applied method of instruction are personal characteristics that 
identify and influence the importance, ranking and content of managerial functions.

The other impact factor is organization itself. The type of organization can differentiate managerial tasks in itself. In the case of an autocratic authoritative or semi-military organization, decision performance, orders and instructions, measurement and control are of greater importance than in a more democratic organization. In a democratic structure of organization, such as a college or a liberal project organization, managerial tasks are completely different. The delegation of tasks, making plausible, authorization or motivational tasks emerges as new managerial functions. Their realization calls forth different managerial skills and potentials, the generation of new managerial roles and expectations.

Size is a key issue among organizational factors. The management of a smaller structure means different tasks, where primarily non-organization communication, information relationships and direct instructive activities are the most vital activities. As we proceed from smaller organizational sizes towards larger ones, managerial tasks grow increasingly complex and differentiated.

The activity of a given organization may exert the greatest influence on management functions. Our earlier investigations suggest that the assessment of the importance and rank of certain tasks may considerably differ according to investigations in the case of a service, marketing or management organization. In terms of a productive organization, decision-making and control were found to be the most essential factors, and the personnel's tasks received the least scores. In the case of service organizations, findings indicate that information, communication and decision making are of key importance, whereas planning and personnel related tasks were ranked the least significant. The managers of management organizations emphasized decisionmaking and planning as vital factors, and ranked instructions almost insignificant. With marketing organizations information, organization, decisionmaking are highlighted among the investigated managerial tasks, whereas the other tasks are considered less important. The type and content of organizational activities exert direct influences on managerial functions, identifying what tasks are to be performed by managers.

The assessment of managerial activities shows differences in terms of the individual's place in the hierarchy of the organization. Top managers usually point out the importance of information, communication, decision-making and the selection of their staff, but consider the process of organization less significant. On the contrary, middle-level leaders find planning, the process of organization and instructions most important; decision making, nonorganization information and the work of their personnel least significant. On lower management levels, control, motivation and instruction are primary managerial tasks, whereas decision-making and staff work are not considered to be important.
For a long time, the literature suggested that managerial functions are independent of the type, activity and situation of the organization, i.e. these functions are constant, they do not change (Torgersen-Weinstock, 1979). Dobák (1995), analyzing managerial functions claim that '...in fact, these are interrelated, integrated activities performed in various orders, often supplemented by mutual feedback. Managers exert management functions in different extent, proportion and with various contents. The time and effort one devotes to certain factors are largely influenced by managerial characteristics, like:

$>$ Management level (top, medium, low)

$>$ Organizational functional area (researchdevelopment, production, sale, financeaccountancy etc.)

$>$ Compatibility between authority and qualifications in the scope of authority and division of labor and regulations, typical of the organization

$>$ The extent subordinates need (or demand) manager participation in certain activities

$>$ The self-conception of one's managerial role.'

Dobák claims that special managerial tasks are manifested in personal direction, coordination and control. 'On some level, every manager has to deal with such activities, but its extent and proportion depend on the situation of the organization and the place the manager takes in it.'

In the course of his analysis on future management problems, Berki (2001) indicates that different content, characteristics and functions of managerial work come into the limelight in the era of information. The rate of restructuring is not likely to slow down, even temporarily, in the $21^{\text {st }}$ century (Kerékjártó, 2001). Thus, tasks related to changes in management functions will gain further importance among future management tasks. As a result of these changes, newer and newer management functions will become enhanced, or even emphasized, while others are pushed to the background or perhaps disappear. Dienesné (2000) suggests that today 'management tasks integrate human management tasks, areas, such as spheres of activity - planning, evaluation, labor availability, performance assessment, incentives, the development of human resources.'

Juhász also points out the increasing role of motivational tasks, saying that motivation emerges as an independent resource in organizations these days, and its proper management is a basic managerial task (Dienesné, 1999).

Láczay (2001) claims that in our days we can see not only shifts in the elite, but changes in the roles and tasks of managerial elite as well. Time factor is increasingly significant in our accelerated, changing world. The time is one of the most restrictive resources and time management is a multisided, complex managerial task (Berki-Berde, 1999).

This multisided affectedness directed our attention towards the analysis of managerial tasks. We sought to formulate responses for the questions 
how and to what extent the activities, tasks of organizations identify the managers' tasks and functions at given organizations. On the basis of surveys by questionnaires, we analyzed the following managerial tasks: information functions, communication, planning, decision making, organization and control. The one interviewed had to qualify factors affecting certain managerial tasks on a scale ranging from one to five. We separated three types of organizations on the basis of the activities, tasks of organizations. The scope of the present study does not allow the publication of all the results related to the above-mentioned managerial functions, so we can only present some of the most interesting investigations.

For our analysis on information resources, we aimed to exploit how managers at companies of different activities evaluate the potentials of gaining information (Figure 1).

Figure 1: Qualification of Information Resources

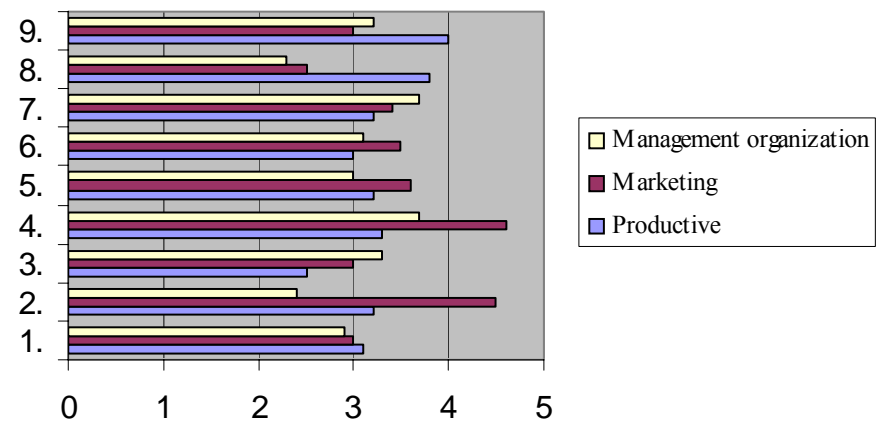

Explanation:

1. Information on technical management, 2. Professional media, 3. Professional relationships, 4. Friendships, 5. Line of information at work, 6. Daily news, media, 7. Laws, orders, 8. Venues, exhibitions, 9. Own experience

The managers of all the three types of organizations consider technical management, i.e. the information role of ministries, professional authorities and institutions important. Marketing organizations highlighted the role of professional media, whereas management organizations downgraded it. Marketing organizations enhanced the importance of information gained through the links of friendship. Surprisingly, they downgraded the roles of venues and exhibitions. Productive organizations emphasized the importance of experience in management and profession.

Planning, as a managerial function, is not easy to investigate. The clear identification of impact factors was not a simple task either. The other problem emerged from the part of those interviewed, and in their interpretation of the factors that we gave them. After several adjustments and reviews we performed our analysis successfully. Figure 2 shows our results.

Figure 2: Evaluation of the Impact Factors of Planning

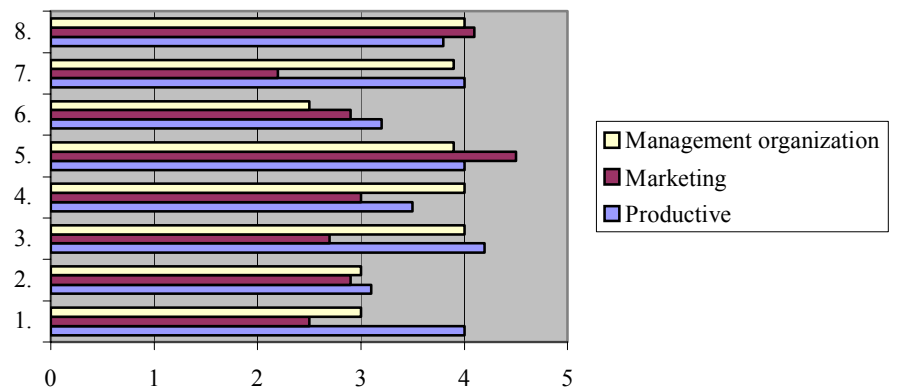

Explanation:

1. Impact of strategic planning, 2. Impact of short-term business planning, 3. Viability of plans, 4. Impact of planning on the methodicalness of processes, 5. Impact of outer (non-organization) changes, 6. Impact of changes inside companies on the viability of plans, 7. Potentials for repetition in the case of plans, 8 . Impact of individual plans

Productive organizations regarded long-term planning as favorable, while marketing and management organizations downgraded it. Significant difference emerges in the assessment of the feasibility of plans, which were ranked high in the case of marketing and management tasks, while low in the case of marketing activities. The impact of outer (non-organization) changes was considered important in the case of all the three types of organization; assessment is similarly single in the 
case of individual plans. The qualification of changes within organizations is clearly low with all the three types. The potentials for the repetition of plans were found good by productive and management organizations, while marketing organizations found them poor. In summary, managers in marketing areas evaluated planning factors less important with low scores, while the managers of productive organizations attributed higher importance to them.

The competencies of decision making, as a managerial task are the least controversial. Managers are often evaluated in terms of their competencies for bringing decisions. Although the definition states' A manager is a person who brings decisions', yet this factor has emerged in the literature, as an independent managerial factor, only recently. As a result, decision-making was investigated only theoretically, and only few studies analyzed the impact factors of decision making. Our investigations aimed to find out what factors and to what extent exert influences on managerial decisions; what is the relationship like between this process and the various types of organizations that we investigated. Our findings are presented on Figure 3.

Figure 3: Qualification of Impact Factors in Decision Making

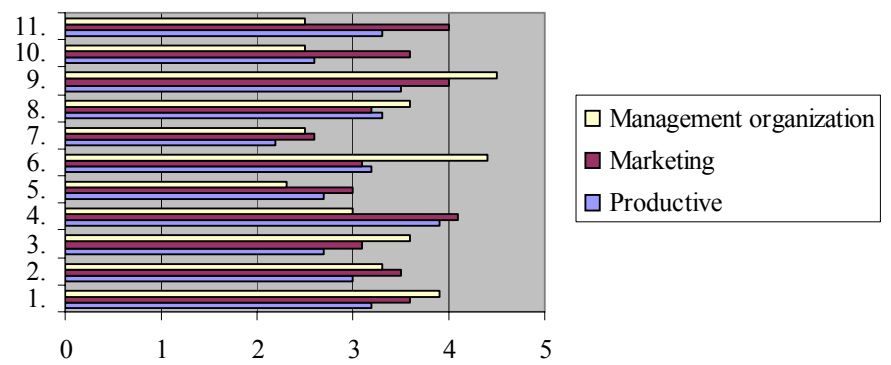

Explanation:

1. Impact of decision-maker's own opinion, 2. Impact of subordinates' opinion, 3. Superiors' expectations, 4. Usefulness, 5. Intuition, 6. Managerial experience, 7. Emotional attitude, 8. Subordinates' interests, 9. The interest of the organization, 10. Managers' interests, 11. Concurrence of own interests with the interests of the organization

The findings of the investigations proved to be relatively balanced. The managers of managerial organizations acknowledge the role of personal opinions in their decision making mostly; but all in all, they evaluate this impact only of medium importance. These concur with the qualification results of the impacts on managerial experience. The impact of subordinates' opinions and superiors' expectations was ranked of medium importance, with no significant differences in the case of various organizational types. The managers of productive and management organizations evaluate the role of intuition insignificant, as in marketing organizations. They also downgrade the role of managerial attitudes. The evaluation of managers' interests is not as simple as above; mainly marketing managers admit the presence of their own interests in their decision-making. The managers of managing organizations claim that the organization's interests rarely concur with their own interests, while marketing managers claim significant concurrence. Control is one of the most important tasks in the management process, a kind of finalizing step. Control is also called the 'feedback' of the management process, on the basis of which we can get information on the mistakes, problems and effectivity of the managerial process. The function of control is less frequently investigated in the literature. We also analyzed only the importance of impact factors in the process of control (Figure 4).

Figure 4: Investigation on the Impact Factors in

Effective Control

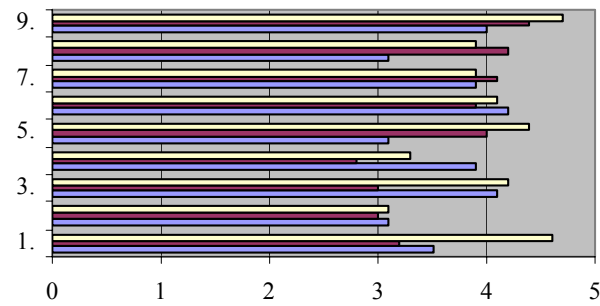

$\square$ Management organization
$\square$ Marketing
$\square$ Productive

Explanation:

1. Role of controls in managerial activities, 2. Importance of deviation from demands, 3 . The essence of control integrated into the process, 4. Importance of continuous controls, 5. Impact of occasional controls, 6. Impact of control on keeping technological disciplines, 7. Impact of performance control, 8. Impact of control on subordinates' behavior, attitude, 9. Control on keeping deadlines 
The managers of productive and marketing organizations rank the role of control of medium importance, whereas the managers of managing organizations rank it highly important. Productive and management organizations evaluate control integrated in the process high, but marketing organizations do not attribute high importance to integrated or continuous control either. Productive organizations downgraded occasional control, in contrast with the opinion of the two other types of organization.

All the three types provided approximately the same assessment results concerning the impact of discipline, performance, behavior-attitude and keeping deadlines. Within these all, productive organizations ranked discipline high, while marketing and especially management organizations found deadline control important.

Our findings lead us to conclude that the realization of certain management functions is influenced by several factors. Without striving for completeness, we only evaluate 9-11 factors as functions. In the evaluation of information sources, organizations differ considerably according to their activities and tasks. In the evaluation of the planning process, the potentials for repetition and feasibility were judged differently, while non-organization changes and individual planning were reported to be equally essential. The results of impact factors on decision-making were also largely different in terms of organizational activities, but all the interviewed enhanced the importance of the interests of the organization. In the course of our analysis on control, we pointed out that the interviewed managers attributed greater importance to issues related to content than to methodological ones.

Management tasks are 'evergreen topics' in management studies, as they can be classified according to several viewpoints; different approaches and contexts, often resulting in surprising conclusions can always identify new tasks.

Our investigations follow Fayol's classical groups based on managerial tasks. We studied the following five tasks in the process of management: information tasks, planning, decision-making, instructions and control. We performed our studies with the inclusion of agricultural organization managers, with questionnaire surveys. The interviewed were asked to qualify the impact factors on the five investigated management tasks on a scale ranging from 1-5. We grouped the investigated organizations as follows:

$<50$ employees - small company

50-250 employees - medium sized company $250<$ employees - large company

We performed our analysis on the basis of company sizes as well, seeking to formulate responses to how sizes influence the qualification of the investigated factors. We present the complex results of our investigations, as well as the final evaluations on all the studied companies and our subevaluations in terms of sizes. Figure 5 shows the findings of information investigations.

Figure 5: Evaluation on the Roles of Information Tasks

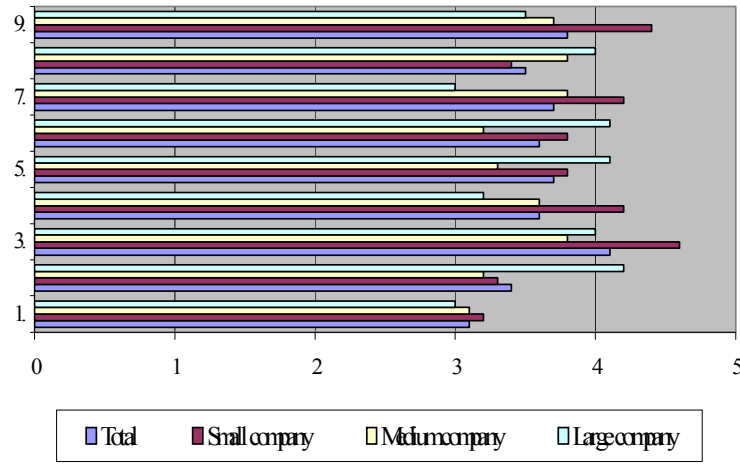

Explanation:

1. Technical management, 2. Professional press, 3. Professional relationships, 4. Friendships, 5. System of information at work, 6. Daily press, media, 7. Laws and decrees, 8. Venues (conferences, presentations), 9. Own experience

Our findings suggest that the interviewed managers regard professional relationships and their own experience as key resources of information, whereas they find the information role of technical management insignificant. Assessments based on company size often coincide with the opinions of managers from different sized companies. Small companies enhanced the information roles of professional relationships, friendships, laws and decrees and own experience. Large companies found the importance of the systems of information at work, venues, exhibitions and conferences significant.

With our analysis on the process of planning (Figure 6), we aimed to formulate responses on the significance and impact of planning by the given managers. 


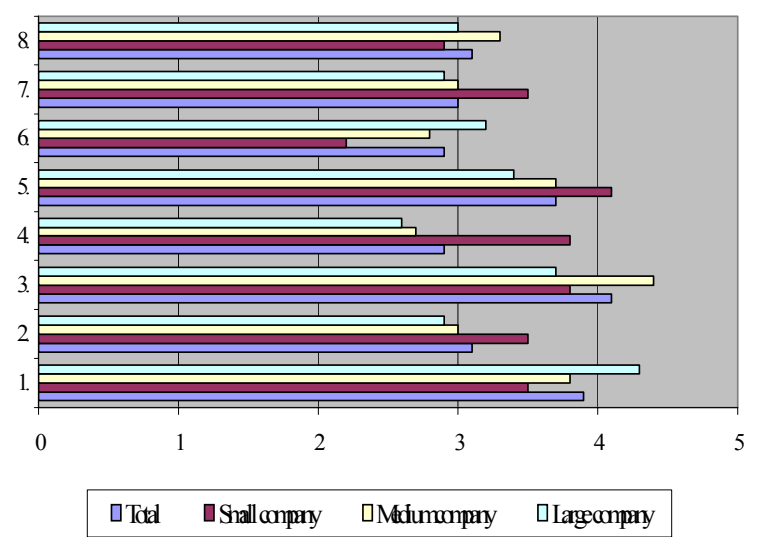

Explanation:

1. Impact of strategic planning, 2. Impact of short-term business planning, 3. Viability of plans, 4. Impact of planning on methodicalness, 5. Non-organization changes, 6 . Changes in organization, 7. The extent of capability in the repetition of plans, 8 . The extent of characteristic individual planning

The total results of our investigations show that the viability of plans, long-term planning and nonorganizational changes are considered to be highly important, whereas inner changes and methodicalness are rather insignificant. Large companies stress the importance of strategic planning; the managers of small companies highlight the impact of short-term planning, whereas medium sized companies point out the modification of plans, while small companies find it of key significance. Company size has no differentiating effects on the other investigated factors. Without the need for completeness, we divided the impact factors of decision-making into 11 groups (Figure 7).

Figure 7: Evaluation on the Impact Factors of Decision-Making

Explanation:

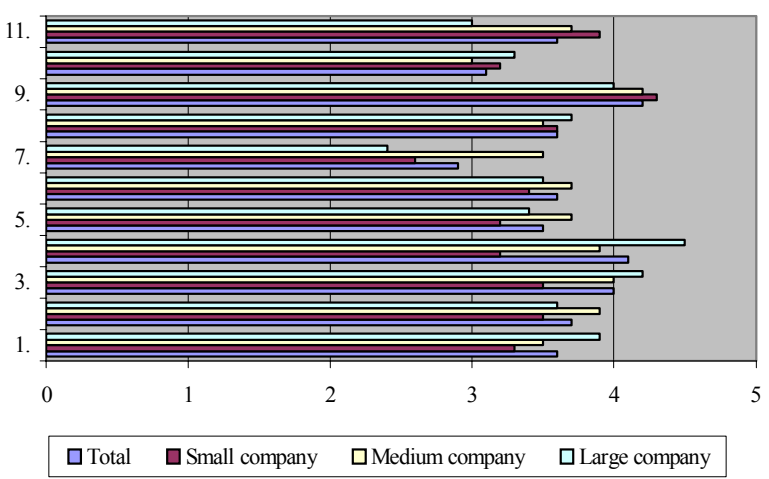

1. Impact of decision-maker's own opinion, 2. Impact of subordinates' opinion, 3. Expectations of superiors, 4. Usefulness, 5. Intuition, 6. Managerial experience, 7. Emotions, attitude, 8. Subordinates' interests, 9. Interests of the company, 10. Managers' interests, 11. Coincidence of private and company interests

The interviewed managers found the impact of all factors significant, the scores of their qualifications can be found in the 'above average' range on the scale of evaluation. The total findings suggest that for the managers of agricultural companies, the key impact factors in decision-making are managers' expectations, usefulness and company interests.

Company size had a major differentiating effect on superiors' expectations, usefulness and emotions, attitude. Attitude is considered insignificant by large the managers of large companies, but usefulness and superiors' expectations are significant for them.

Orders, instructions can be interpreted as measures for the implementation of decisions. These are among the key managerial tasks as "every decision is worth as much as the extent of its viability'. Figure 8 shows the findings on the success of instructions, orders. 


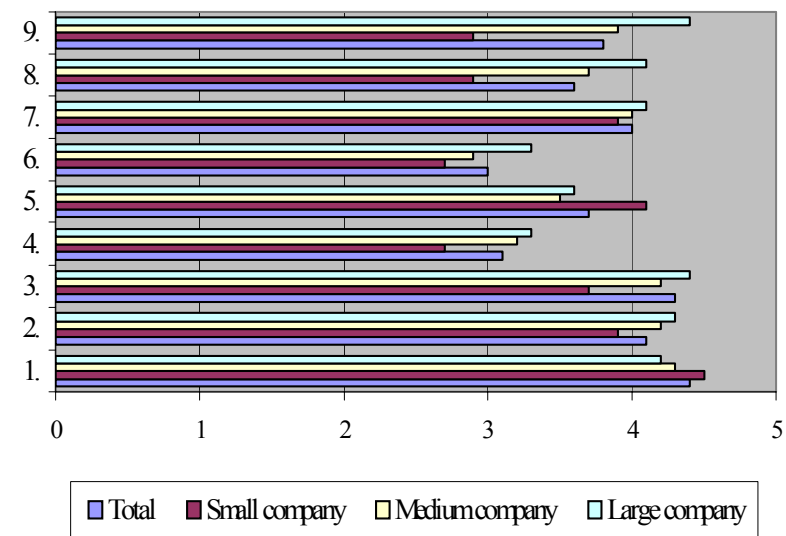

Explanation:

1. Clarity of instructions, 2. Its harmony with the decision, 3. Concreteness of the decision, 4. Impact of written records, 5. Impact of oral instructions, 6. Frequency of instructions, 7. Checking of execution, 8. Competency, 9. Support for implementers

The interviewed managers point out the content elements of orders and instructions, i.e. the concreteness and clarity of instructions, as well as their harmony with decisions. The control of implementation is highlighted in every investigation. Surprisingly, written instructions are downgraded in contrast with oral ones. Further details on this show that its reason lies in the answers of small company leaders, as they do not attribute high importance to the use of written records, but stress the importance of oral instructions. The same tendency can be seen in the evaluation of competencies and support for implementation. Managers of small companies do not find any of them essential, but all these factors get evaluated higher with size growth.

Figure 9 shows the findings in the impact factors of instructions.

Figure 9: Qualification of Control Factors

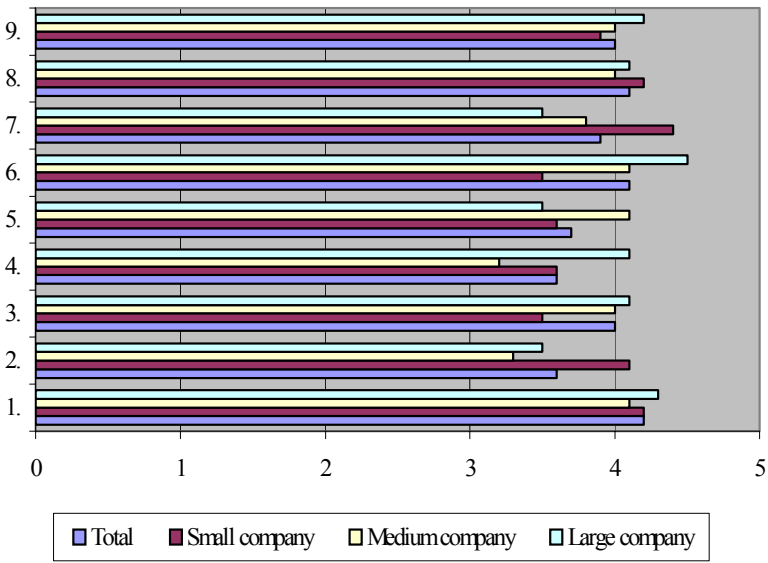

Explanation:

1. The role of control in managerial activities, 2. Importance of deviation from demands, 3. Impact of control integrated in the process, 4. Importance of continuous controls, 5. Impact of occasional controls, 6. Impact of control in keeping technological disciplines, 7. Impact of performance control, 8. Control of keeping deadlines, 9. Control on keeping deadlines

Our findings suggest that managers find control highly important. They ranked the methods of control as being similarly significant, enhancing the impact of control integrated in the process. Out of the content elements of control, large companies regarded technological disciplines, attitude and behavior as important, while small companies pointed out performance control.

Our findings indicate that company managers attribute higher than average importance to the tasks of managerial activities. Company size exerts a considerable influence on the qualification and ranking of managerial tasks. Relations and venues play important roles in information tasks, while the feasibility of plans is highlighted in planning. In the process of decision-making, usefulness and company interests are of key significance. In the case of instructions and decision-making, content elements are dominant in contrast with formal ones. 


\section{REFERENCES}

Angyal, A. (1999): Mastertricks in Management. Kossuth Kiadó, Budapest

Berki, S. (1998): Seauton of Gnoth. Humánpolitikai Szemle, 5-6. Budapest

Berki, S. (2000): Information Management in Food Industry, Saint Stephen University, College of Economics and Agriculture, Gyöngyös, $7^{\text {th }}$ International Agro-economic Scientific Days, Gyöngyös, 28-29 March, 2000. 1. 95-100.

Berki, S. (2001): Future Management problems. 'Integration of Innovation, Science and Practice in the Agrarium of the Millennium', Conference Publication, Gödöllő

Berki, S.-Berde, Cs. (1999): '....Said the Snail and....' Humánpolitikai Szemle, 7-8. Budapest

Berki, S.-Berde, Cs. (2000): The Resurrection of the Salesman. Humánpolitikai Szemle, 7-9. Budapest

Dienesné, K. E. (1999): Comparative Studies on Values Preferencies among Agricultural Experts in the East Tisza Region. DATE Agricultural Scientific Days in the East Tisza Region, Debrecen

Dienesné, K. E. (1999): Managerial Motivation. Publication of the East Tisza Region Scientific Days, Debrecen

Dienesné, K. E. (2000): Management Tasks in Production Management. XXVIII. Publication of the Óvár Scientific Days, Mosonmagyaróvár
Dienesné, K. E. (2000): Managerial Tasks in Production Management. Roles of Human Strategies in the Development of Agricultural Enterprises. XXVIII. Óvár Scientific Days, Mosonmagyaróvár

Dienesné, K. E.-Berde, Cs.-Bilanics, Á. (2000): Company Size and Irrigation. Human management for Agricultural Students of Engineering. College Textbook, Nyíregyháza

Dobák, M. (1995): Management-organization. Aula Kiadó, Budapest

Huitfeldt, T.-Diezricson, J. E.-Drangsholt, O. M.-Mohn, C. R. (1993): Modern Management, EDE-Hungary, Budapest

Juhász, Cs. (2001): Motivation in Various Agricultural Organizations. Agricultural Scientific Publications 1., Debrecen

Kerékjártó, G. (2001): Managers' Opinion on Recent Changes. XLIII. Georgikon Days, Keszthely

Láczay, M. (1999): Social Impact of Hungarian Land Reforms, Periodika Publication, 15. Ungvár

Láczay, M. (2001): Restructuring in the Elite and their Roles in the Hungarian and Szabolcs-Szatmár-Bereg Society. 'Integration of Innovation, Science and Practice in the Agrarium of the Millennium', Conference Publication, Gödöllő

Torgersen, P. E. E.-Weinstock, I. T. (1979): The Integrated Concept of Management. Közgazdasági és Jogi Kiadó, Budapest 